\title{
Hydroalcoholic extract of Arum orientale ameliorates myocardial infarction induced by isoproterenol in rats
}

\author{
Asal JAVIDMEHR 1 (D), Samin ABBASZADEH 1 (D), Mehdi KIAN 2 (D), Sanaz HAMEDEYAZDAN 3 (D), \\ Hamid SORAYA $1,4 *$ (D) \\ 1 Department of Pharmacology, Faculty of Pharmacy, Urmia University of Medical Sciences, Urmia, Iran. \\ 2 Department of Comparative Biomedical Sciences, School of Advanced Medical Sciences and Technologies, Shiraz \\ University of Medical Sciences, Shiraz, Iran. \\ 3 Department of Pharmacognosy, Faculty of Pharmacy, Tabriz University of Medical Sciences, Tabriz, Iran. \\ 4 Experimental and Applied Pharmaceutical Research Center, Urmia University of Medical Sciences, Urmia, Iran. \\ * Corresponding Author. E-mail: soraya.h@umsu.ac.ir; hamid_soraya2000@yahoo.com (H.S.); Tel. +98-44-3275 49 96; \\ Fax: +98-44-32754990.
}

Received: 30 April 2020 / Revised: 31 October 2020/ Accepted: 23 November 2020

\begin{abstract}
Arum species have antioxidant, antimicrobial, and anti-cancer effects. However, there is no study on its possible cardioprotective effects. In the present study, the protective effects of hydro-alcoholic extract of Arum orientale (A. orientale) on isoproterenol-induced myocardial infarction (MI) were evaluated. For induction of MI the rats were received isoproterenol $(100 \mathrm{mg} / \mathrm{kg})$ for two consecutive days, whereas treated groups received 40,80 and 160 $\mathrm{mg} / \mathrm{kg} /$ day of hydroalcoholic extract of A.orientale intraperitoneally (ip) $20 \mathrm{~min}$ before each Isoproterenol injection. Isoproterenol-induced MI significantly increased myocardial necrosis and neutrophil infiltration. Histopathological analysis showed that $A$. orientale at dose of $160 \mathrm{mg} / \mathrm{kg}$ significantly reduced necrosis and neutrophil infiltration in the heart tissue $(\mathrm{P}<0.046$ and $\mathrm{P}<0.048$, respectively). Induction of $\mathrm{MI}$ also increased myeloperoxidase $(\mathrm{MPO})$ activity and peripheral neutrophil percent. While A. orientale similarly decreased MPO activity and peripheral neutrophils in blood $(\mathrm{P}<0.021 \mathrm{p}<0.042$ respectively) at dose of $160 \mathrm{mg} / \mathrm{kg}$. Administration of the extract markedly decreased serum malondialdehyde level at dose of $80 \mathrm{mg} / \mathrm{kg}$ and creatine phosphokinase (CPK) activity with all doses. Our results for the first time reported potential cardioprotective effects of A. orientale that partially can be through suppression of inflammatory responses and reduction of lipid peroxidation following MI. However, any suggestions for potential use in MI needs further studies.
\end{abstract}

KEYWORDS: Arum; Myocardial Infarction; neutrophil; lipid peroxidation; creatine kinase

\section{INTRODUCTION}

Despite the advances and increase of awareness in personal and public health care, cardiovascular diseases, prevalently myocardial infarction (MI) are of the most common causes of human death globally [1]. MI occurs due to imbalance between coronary blood supply and cardiomyocytes oxygen demand [2] Induction of oxidative stress caused by generation of reactive oxygen species (ROS) in cardiomyocytes is a leading factor in pathophysiology of MI. Myocardial necrosis or cell death due to MI is directly associated to ROS generation [3]. Besides, ROS can trigger signaling cascades, which predominantly produce inflammatory cytokines that results in cardiac depression. In response to MI, an intense inflammatory reaction initiates, which is pivotal for cardiac remodeling and repair after MI [4]. Neutrophils are the key mediators of this process that regulates removal of necrotic cardiomyocytes [5]. Although initiation of inflammatory response is beneficial for cardiac remodeling and healing process after MI, but over-activation of inflammation signaling leads to adverse secondary complications in infarcted heart [4]. Thus, suppression of post-inflammation response seems substantial.

Herbal plants are used in East from ancient times and recently are being popular in western consumers [6]. Arum genus, which belongs to Araceae family, is a flowering plant native to western Asia, northern Africa, Mediterranean region and Europe [7]. Arum species are used as herbal remedies in traditional medicine of different countries. These plants have exhibited various pharmacological activities, including antioxidant, anticancer, antimicrobial, and anti-nociceptive activities [8-11]. Arum species have

How to cite this article: Javidmehr A, Abbaszadeh S, Kian M, Hamedeyazdan S, Soraya H. Hydroalcoholic extract of Arum orientale improves myocardial infarction induced by isoproterenol in rats. J Res Pharm. 2021; 25(1): 80-88. 
antioxidant and free radical scavenging potential owing to presence of polyphenols and flavonoids in these plants [11]. Dietary antioxidants and flavonoids of herbal plants could be beneficial for cardiovascular health [12]. To the best of our knowledge, there is no study hitherto on possible cardioprotective potentials of Arum species. Arum orientale (A. orientale) is one of the Arum species, which grows in Iran, and so far, no study conducted on the effects of $A$. orientale on cardiovascular diseases.

Isoproterenol (ISO) is a synthetic $\beta$-adrenergic receptor agonist which its administration at high doses induces infarct-like lesions in animal models [13]. Therefore, induction of MI in rats by using ISO is a suitable model to evaluate cardioprotective effects of different compounds [14]. In the present study, we evaluated the cardioprotective effects effects of hydro-alcoholic extract of A. orientale on myocardial necrosis, neutrophil infiltration, myeloperoxidase (MPO) activity, lipid peroxidation, and creatine phosphokinase (CPK) activity in ISO-induced MI in rats.

\section{RESULTS}

\subsection{Effects of hydro-alcoholic extract of A. orientale on myocardial necrosis and neutrophil infiltration}

Our histological examination showed regular arrangement of myocardial fibers with no apparent necrosis and neutrophil infiltration in control group. MI group showed widespread subendocardial necrosis and myocardial neutrophil infiltration (Figure 1A). Treated group especially Arum $160 \mathrm{mg} / \mathrm{kg}$ significantly reduced myocardial neutrophil infiltration and necrosis $(\mathrm{P}<0.046)$ as showed in Figures 1B and C.
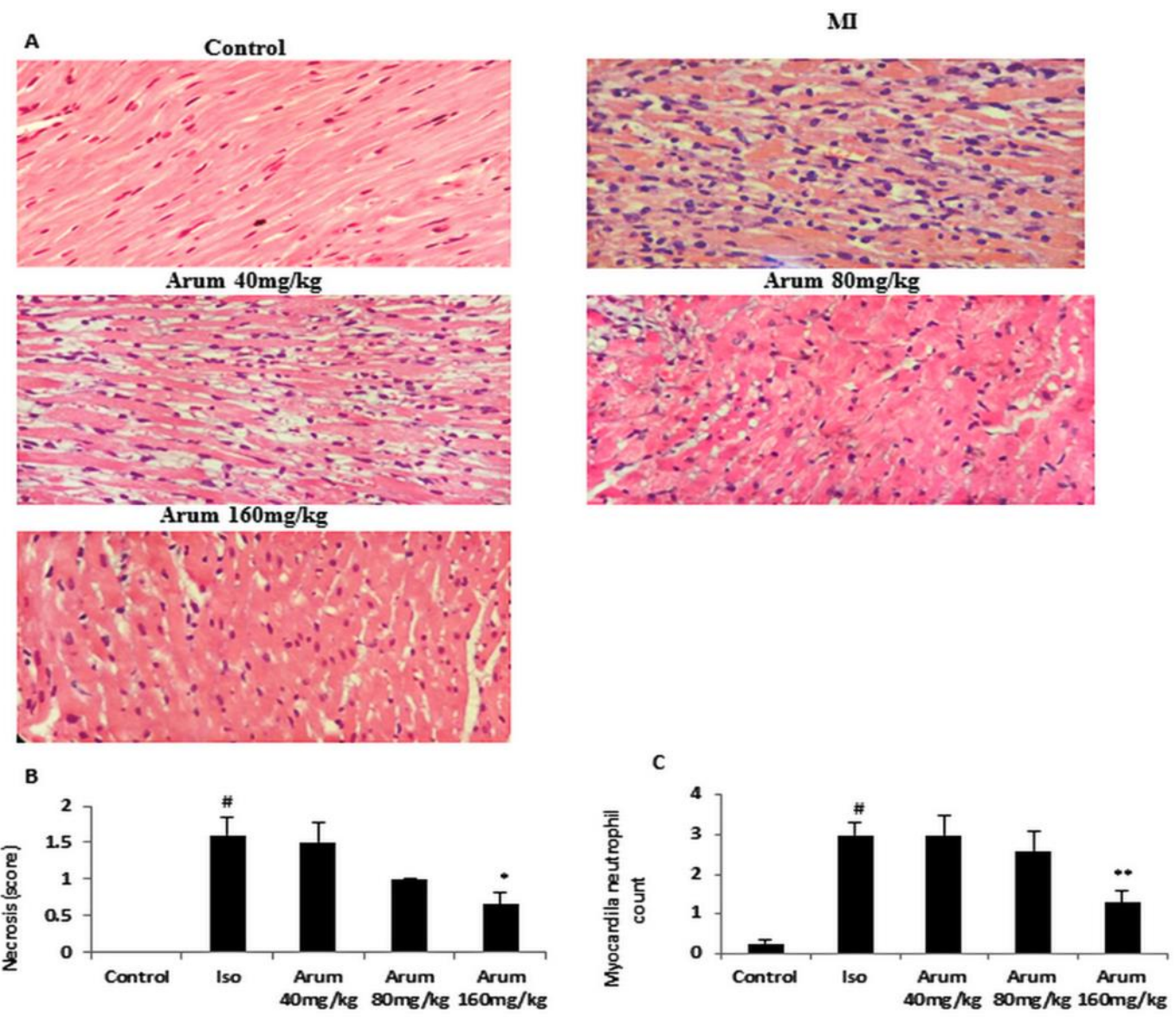

Figure 1. (A) Histopathological observation in the myocardial tissues of the rats treated with hydroalcoholic extract of $A$. orientale. In order to quantify the histological changes, cardiomyocyte necrosis (B) and myocardial neutrophil count (C) were graded in the rat's cardiac apex tissues after hematoxylin and eosin (H\&E) staining (40x magnification). Values are the mean $\pm \operatorname{sem}(n=6) . \# P<0.001$ compared with control group; ${ }^{*} \mathrm{P}<0.05$ as compared with MI group using one way ANOVA with Tukey post hoc test. 


\subsection{Effects of hydroalcoholic extract of $A$. orientale on lipid peroxidation}

For determination of lipid peroxidation, malondialdehyde (MDA) level were measured in the serum. MDA levels increased significantly in MI group in compare to control group $(\mathrm{P}<0.01)$. Treatment only with moderate dose of the hydroalcoholic extract of A. orientale $(80 \mathrm{mg} / \mathrm{kg})$ markedly diminished MDA level $(\mathrm{P}<0.036)$ that shows this effect is dose-independent (Figure 2).

\subsection{Effect of hydroalcoholic extract of $A$. orientale on the activity of myocardial MPO and neutrophil} count in blood

ISO injection resulted in an increase in peripheral neutrophil count $(\mathrm{P}<0.007)$ and leukocyte infiltration into the myocardial tissue, as measured by an increase in MPO activity $(\mathrm{P}<0.015)$. Treatment with the extract was found to reduce the peripheral neutrophil percent $(\mathrm{P}<0.042)$ and MPO activity in the myocardial tissue with the most profound reduction at A. orientale $160 \mathrm{mg} / \mathrm{kg}(\mathrm{P}<0.021)$ (Figure 3).

\subsection{Effect of hydroalcoholic extract of A. orientale on CPK activity}

As can be seen in Figure 4, the total creatine kinase increased significantly in MI group in comparison to control $(\mathrm{P}<0.000)$. Treatment with the extract at all three doses caused profound reduction in serum CPK level in comparison to MI group $(\mathrm{P}<0.000)$.

\section{DISCUSSION}

The present study investigated the effects of hydro-alcoholic extract of A. orientale on cardiac neutrophil recruitment and necrosis, MPO activity, lipid peroxidation, and CPK activity in ISO-induced MI. Our results showed that administration of A. orientale $(160 \mathrm{mg} / \mathrm{kg})$ significantly reduced necrosis, neutrophil infiltration and MPO activity in the heart. Treatment with the hydroalcoholic extract of A. orientale ( 80 $\mathrm{mg} / \mathrm{kg}$ ) markedly diminished lipid peroxidation. In addition, treatment with the extract at all three doses reduced serum CPK level in comparison to MI group. According to our findings, treatment with hydroalcoholic extract of $A$. orientale can be cardioprotective in myocardial infarction through its antiinflammatory and anti-oxidant effects.

Histopathological findings showed that MI induction with ISO caused necrosis in the heart tissue, which is similar to prior studies $[15,17,18]$. The mechanism of necrosis following MI has well elucidated in literatures. Excessive influx of $\mathrm{Ca}^{2+}$ increases contractions of myocardium and consequently, increases myocardial oxygen need. These circumstances lead to ATP depletion and leakage of electron from respiratory chain. Released electrons react with oxygen molecules and synthesize ROS, which lead to oxidative damages and finally result in myocardial necrosis [19-21].

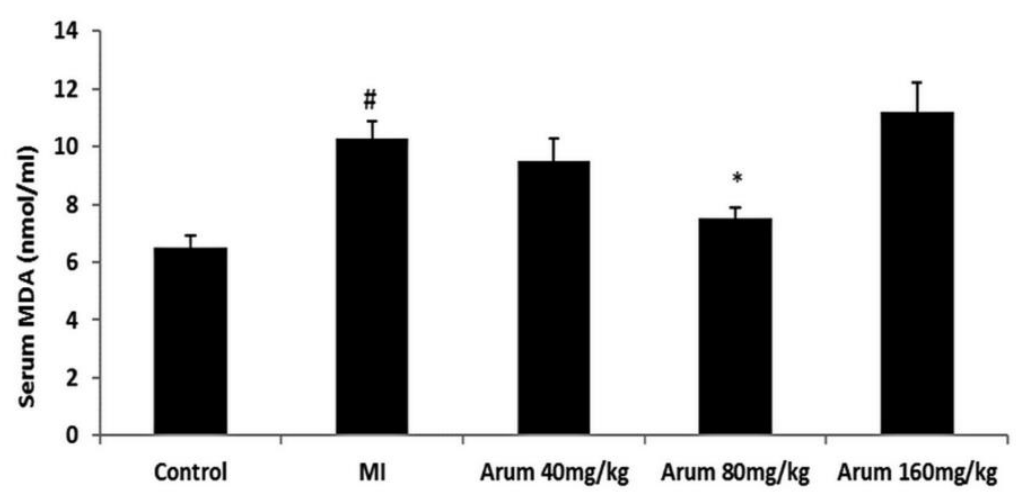

Figure 2. After treatment with hydroalcoholic extract of $A$. orientale, serum MDA levels were measured in rats with isoproterenol-induced MI. Values are mean \pm sem $(n=6)$. \# $\mathrm{P}<0.05$ compared with control group; ${ }^{*} \mathrm{P}<0.05$ as compared with MI group using one way ANOVA with Tukey post hoc test. 


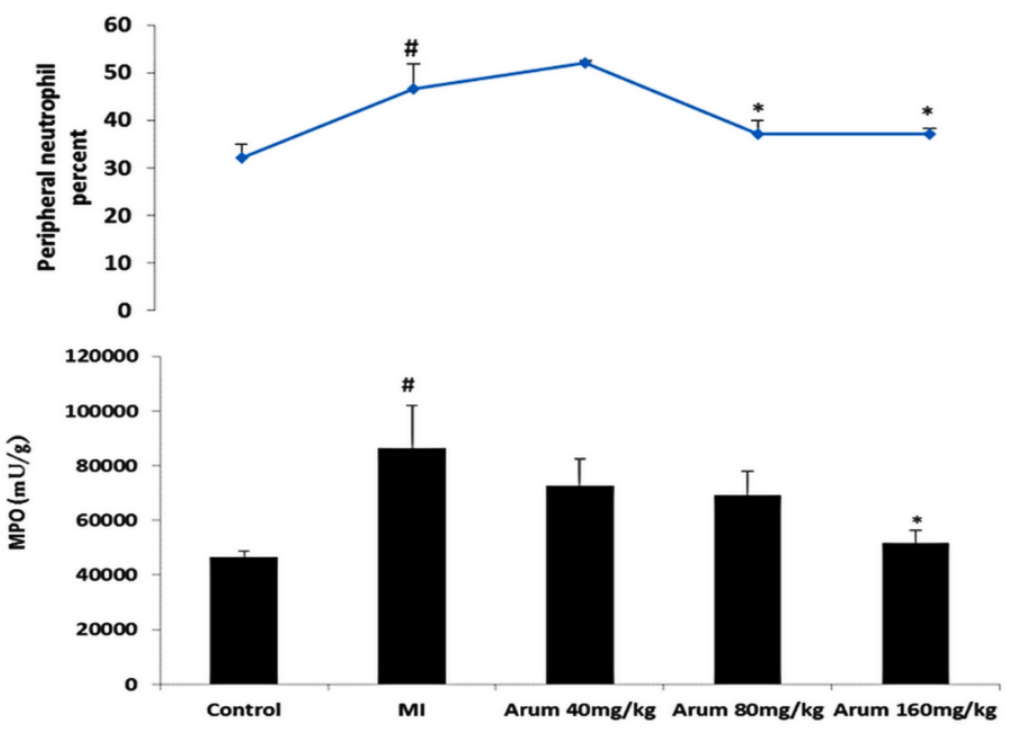

Figure 3. After treatment with hydroalcoholic extract of A. orientale, MPO activity (bar graphs) and neutrophil count in blood (line graph) were determined in rats with isoproterenol-induced MI. Values are mean \pm sem $(n=6)$. \#P<0.01 compared with control group; ${ }^{*} \mathrm{P}<0.05$, as compared with MI group using one way ANOVA with Tukey post hoc test.

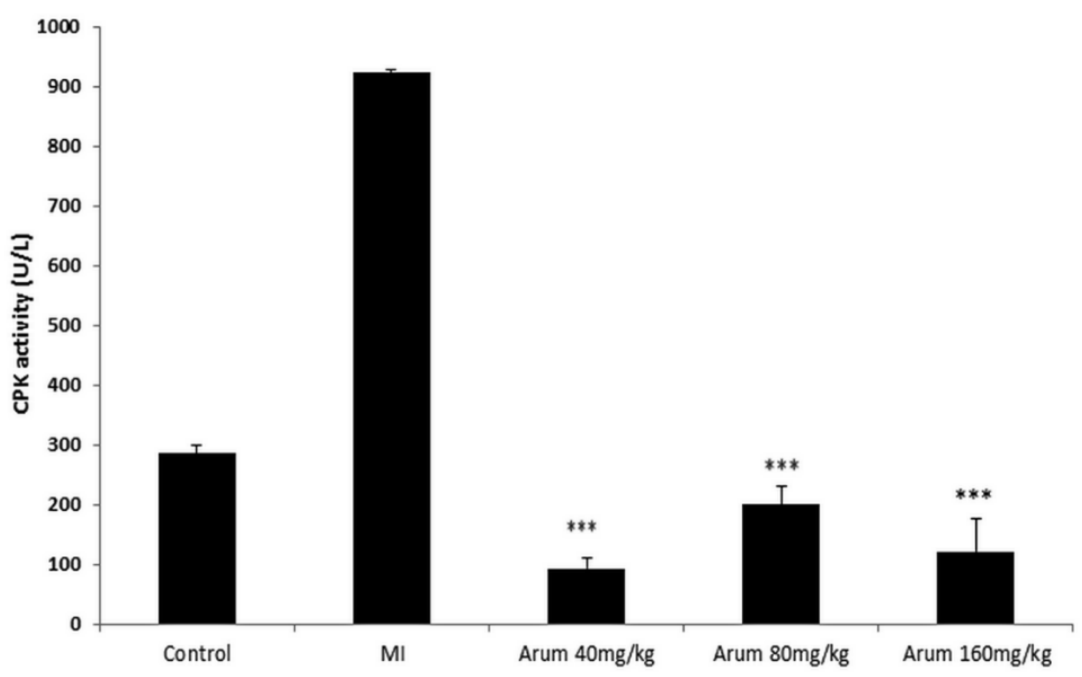

Figure 4. After treatment with hydroalcoholic extract of $A$. orientale, CPK activity was measured in rats with isoproterenol-induced MI. Values are mean \pm sem $(n=6)$. \# $P<0.01$ compared with control group; ***P $<0.001$, as compared with MI group using one way ANOVA with Tukey post hoc test.

Minimizing of myocardial necrosis is one of the effective strategies to prevail over injuries following $\mathrm{MI}$ and optimizing post-MI cardiac healing [15, 22]. Our results showed that administration of $A$. orientale at dose of $160 \mathrm{mg} / \mathrm{kg}$ markedly decreased necrosis. Therefore, this plant has advantage on post-MI heart injuries. As mentioned above, excessive activation of post-MI inflammation response negatively affects infarcted heart. Researchers have suggested anti-inflammatory therapy is a good strategy to decrease size of necrosis in infarcted heart [22-24]. Studies on MI canine models revealed that anti-inflammatory treatment reduced size of infarction following MI [25-27]. Considering that induction of inflammation in post-MI heart depends on neutrophils, $[5,28]$ thereby reduction of neutrophils could be advantageous in minimizing of myocardial necrosis. Evidence have demonstrated that depletion of neutrophils considerably decreased infarcted size and myocardial injury in canine models [26, 27]. Induction of MI in the present study increased peripheral neutrophil percent, serum MPO activity and neutrophil numbers in myocardium. These results indicated occurrence of inflammation following MI and are in line with previous studies $[1,15,17,29,30]$. 
In the current study we demonstrated that, A. orientale reduced numbers of neutrophils in the myocardium. In addition, administration of A. orientale significantly reduced percent of peripheral neutrophils and MPO activity in infracted heart. Therefore, administration of A. orientale hydroalcoholic extract could suppresses inflammation response following MI induction and results in reducing necrosis score in MI-rats. It is noteworthy; this study is the first report on anti-inflammatory effects of $A$. orientale. Our preliminary study (unpublished data) revealed that A. orientale possesses alkaloids, flavonoids, saponins, and tannins compounds. Literature have reported these compounds have anti-inflammatory and antioxidant activities [31-34]. Therefore, the anti-inflammatory effects of $A$. orientale might be due to the existence of these compounds in its structure. There are few studies on possible effects of Arum species on inflammation, which are in contrast with present research. It has been reported that A. palaestinum had no anti-inflammatory activity[35]. Another study by Alencar et al. [36] have indicated A. maculatum lectinderived from its tuber has pro-inflammatory effects.

Induction of MI by ISO injection significantly elevated MDA levels of serum that is similar to prior researches [1, 18]. MDA is a biomarker of lipid peroxidation and indicates oxidative damages in cardiovascular diseases [37]. Our results demonstrated that only moderate doses of hydroalcoholic extract of A.orientale decreased serum MDA levels that shows dose independent effects. In line with our results, Janakat \& Al-Thnaibat [38] showed that aqueous extracts of $A$. dioscoridis has anti-lipid peroxidation activity. These findings could be due to presence of flavonoids and phenolic compounds in structure of Arum species because these compounds have radical scavenging and antioxidant activities[11].

$\mathrm{CPK}$ is an enzyme that exist in various tissues including the myocardium and skeletal muscle. Increasing in serum activity of CPK is indicator of cardiac and muscle disorders [39]. Induction of MI in the present study, increased CPK activity in serum that is in parallel with previous reports. However, treatment of animals with A. orientale hydroalcoholic extract considerably reduced CPK. As CPK is partially a marker of myocardial damage, [40] these findings indicate cardioprotective potential of A. orientale. The lack of phytochemical analysis of the plant to determine effective compound involved in cardioprotection is a limitation of this study.

\section{CONCLUSION}

To the best of our knowledge, this is the first study reporting potential cardioprotective effects of $A$. orientale. This protection partially can be through suppression of inflammatory responses and reduction of lipid peroxidation following MI. However, any suggestions for potential use in MI needs further studies. Finally, we suggest that the effects of this plant be tested in other animal models of MI.

\section{MATERIALS AND METHODS}

\subsection{Plant collection and extraction}

Aerial parts of A. orientale were collected from its wild population growing in Aras district, West Azerbaijan, Iran in June 2017. Voucher samples were maintained for reference in the Herbarium of School of Pharmacy, Urmia University of Medical Sciences (No: HUPS-506). The entire plant materials were washed and kept under shade at room temperature till the whole parts became well dried followed by powdering using a grinder (Moulinex, France). Then $130 \mathrm{~g}$ of plant powder was mixed in ethanol $70 \%$ (2.5L) for $24 \mathrm{~h}$ at room temperature in order to extract maceration. The extraction process was repeated two more times, Whatman paper filter was used to filter the extract, and eventually ethanol was evaporated by using a rotary evaporator (Heidolph, Germany), at $45^{\circ} \mathrm{C}$ under vacuum.

\subsection{Animals}

Healthy adult male Wistar rats $(260 \pm 20 \mathrm{~g}, 8-10$ weeks old) were used in this study. The animals were obtained from Animal House of Urmia University of Medical Sciences and housed there under standardized conditions (12-h light/dark cycle, temperature $22 \pm 1^{\circ} \mathrm{C}$ and $50 \pm 10 \%$ humidity) with food and water available ad libitum. All animal experiments were performed in accordance with the Guide for the Care and Use of Laboratory Animals published by the US National Institute of Health (NIH Publication, 8th Edition, 2011) and approved by ethics committee of Urmia University of Medical Sciences (ir.umsu.rec.1396.139). 


\subsection{Experimental procedures}

For grouping, the animals were randomly divided into five groups $(\mathrm{n}=6$, each group). In control group, rats received a subcutaneous $(s c)$ injection of normal saline $(0.5 \mathrm{ml})$ for two consecutive days. Rats in MI group received an intraperitoneally (ip) injection of normal saline for two days and also received (sc) injection of ISO $(100 \mathrm{mg} / \mathrm{kg} /$ day) for 2 consecutive days at an interval of $24 \mathrm{~h}$. Rats in groups 3 to 5 were $s c$ injected with ISO $(100 \mathrm{mg} / \mathrm{kg} /$ day) and were treated with ip injection of hydroalcoholic extract of $A$. orientale at doses of 40,80 , and $160 \mathrm{mg} / \mathrm{kg} /$ day for two consecutive days at an interval of $24 \mathrm{~h}$. At the end of experiment, animals were anesthetized by an ip injection of a mixture of ketamine $(60 \mathrm{mg} / \mathrm{kg})$ and xylazine $(10 \mathrm{mg} / \mathrm{kg})$ and blood samples were obtained from hepatic portal vein. Then, animals were euthanized by an overdose of the anesthetics and tissue sampling were done. The overall mortality rate was $25-37 \%$. Actually, the rats who died at the beginning of the study for reasons, such as injections of isoproterenol or anesthetic were excluded from the study.

\subsection{Histopathological study}

At the end of experiment (on day 3) cardiac tissues rapidly were removed and cardiac apex were isolated. Cardiac specimens were fixed in 10\% formaldehyde, then were embedded in paraffin, sectioned at five $\mu \mathrm{m}$ with microtome, and stained with hematoxylin and eosin (H\&E) for evaluation of necrosis and neutrophil infiltration. Two trained person (at least one pathologist) were quantified histological changes by scoring as follows: 1, 2, 3, and 4 for low, moderate (small multifocal degeneration with slight degree neutrophil infiltration), high (extensive degeneration and/or diffuse neutrophil infiltration), and intensive (necrosis with diffuse neutrophil infiltration) pathological changes, respectively (40x magnification) [15].

\subsection{Malondialdehyde (MDA) measurement}

For determination of serum lipid peroxidation, as a marker of oxidative stress, blood samples were taken from portal vein and serum was separated with centrifugation at $3000 \mathrm{rpm}$ for $5 \mathrm{~min}$. Lipid peroxidation was quantified by determination of MDA levels. In brief, $0.5 \mathrm{ml}$ of isolated serum was added to $2.5 \mathrm{ml}$ of $20 \%$ trichloroacetic acid (TCA). Then $1 \mathrm{ml}$ of $0.6 \%$ thiobarbituric acid (TBA) was added, mixed, and then warmed for $30 \mathrm{~min}$ in a boiling water bath followed by rapid cooling. Then $4 \mathrm{ml}$ of n-butyl alcohol was added and centrifuged at $3000 \mathrm{rpm}$ for $15 \mathrm{~min}$. MDA content in the plasma was determined from the absorbance at $535 \mathrm{~nm}$ by spectrophotometer. N-buthyl alcohol was used as a blank. The results were presented as $\mathrm{nmol} / \mathrm{ml}$ plasma [16].

\subsection{Neutrophil counting in blood}

In order to determine the number of neutrophils in blood, fresh blood samples were smeared on the clean slides and the percent of neutrophils were counted at 100× magnificationin optical microscope after Gimsa staining [15].

\subsection{MPO Assay}

For quantifying the activity of neutrophils in cardiac tissue, MPO was measured. Briefly, cardiac tissues were homogenized in $50 \mathrm{mM}$ potassium phosphate buffer $(\mathrm{pH}=6)$ containing $0.5 \%$ hexadecyltrimethyl ammonium bromide (HTAB) to solubilize the enzyme. The tissues were then freeze-thawed three times and sonicated for $20 \mathrm{~s}$ and centrifuged at $11,000 \times \mathrm{g}$ for $30 \mathrm{~min}$ at $4{ }^{\circ} \mathrm{C}$. Then, $100 \mu \mathrm{l}$ of the upper clear supernatant was added to $2.9 \mathrm{ml}$ solution of $50 \mathrm{mM}$ potassium phosphate buffer ( $\mathrm{pH}$ 6) containing 0.167 $\mathrm{mg} / \mathrm{ml}$ of O-dianisidine hydrochloride and $0.0005 \% \mathrm{H}_{2} \mathrm{O}_{2}$. After five minutes, $100 \mu \mathrm{l}$ of $1.2 \mathrm{M}$ hydrochloric acid was added to stop the reaction. MPO content in the myocardial tissue was determined from the absorbance at $460 \mathrm{~nm}$ by spectrophotometer (Cecil 9000, UK). The results were expressed as miliunits of MPO in gram tissue[15].

\subsection{CPK Activity}

CPK activity was measured according to the instructions provided in a commercially available assay kit (Pars Azmun, Iran).

\subsection{Statistical analysis}

Data were presented as mean \pm sem. One-way ANOVA was used to make comparisons between the groups. If the ANOVA analysis indicated significant differences, a Tukey post hoc test was performed for 
pairwise comparison. SPSS 16 were used for statistical analysis. Any differences between the groups were considered significant at $\mathrm{P}<0.05$.

Acknowledgements: The present study was supported by a grant from the Research Vice Chancellors of Urmia University of Medical Sciences, Urmia, Iran.

Author contributions:Concept- H.S.; Design- H.S.,A.J., S.A.; Supervision- H.S.; Resource- H.S.; Materials- H.S., S.H.; Data collection and processing- A.J., S.A., S.H.; Analysis and Interpretation- H.S.; Literature Search- A.J., S.A., M.K.; Writing - A.J., S.A., M.K.; Critical Reviews - H.S., A.J., S.A., M.K., S.H.

Conflict of interest statement: None declared.

Ethics committee approval: All experiments conducted in this study were approved by ethics committee of Urmia University of Medical Scienceswith the approval number of ir.umsu.rec.1396.139 on 2017.

\section{REFERENCES}

[1] Nahar K, Kabir F, Islam P, Rahman MM, Al Mamun MA, Faruk M, Subhan N, Rahman GMS, Reza HM, Alam MA. Cardioprotective effect of Amaranthus tricolor extract in isoprenaline induced myocardial damage in ovariectomized rats. Biomed Pharmacother. 2018; 103: 1154-1162. [CrossRef]

[2] Boudina S, Laclau MN, Tariosse L, Daret D, Gouverneur G, Bonoron-Adele S, Saks VA, Dos Santos P. Alteration of mitochondrial function in a model of chronic ischemia in vivo in rat heart. Am J Physiol Heart Circ Physiol. 2002; 282: H821-831. [Crossref]

[3] Di Filippo C, Cuzzocrea S, Rossi F, Marfella R, D'Amico M. Oxidative stress as the leading cause of acute myocardial infarction in diabetics. Cardiovasc Drug Rev. 2006;24: 77-87. [CrossRef]

[4] Frangogiannis NG. The inflammatory response in myocardial injury, repair, and remodelling. Nat Rev Cardiol. 2014;11:255-265. [CrossRef]

[5] Ma Y, Yabluchanskiy A, Lindsey ML. Neutrophil roles in left ventricular remodeling following myocardial infarction. Fibrogenesis Tissue Repair. 2013;6:11. [CrossRef]

[6] Tachjian A, Maria V, Jahangir A. Use of herbal products and potential interactions in patients with cardiovascular diseases. J Am Coll Cardiol. 2010; 55: 515-525. [CrossRef]

[7] El-Desouky SK, Kim KH, Ryu SY, Eweas AF, Gamal-Eldeen AM, Kim YK. A new pyrrole alkaloid isolated from Arum palaestinum Boiss. and its biological activities. Arch Pharm Res. 2007; 30: 927-931. [CrossRef]

[8] Qnais E, Bseiso Y, Wedyan M, Alkhateeb H. Evaluation of Analgesic Activity of the Methanol Extract from the Leaves of Arum palaestinum in Mice and Rats. Biomed Pharmacol J. 2017; 10: 1159-1166. [CrossRef]

[9] Cole C, Burgoyne T, Lee A, Stehno-Bittel L, Zaid G. Arum Palaestinum with isovanillin, linolenic acid and betasitosterol inhibits prostate cancer spheroids and reduces the growth rate of prostate tumors in mice. BMC Complement Altern Med. 2015; 15: 264. [CrossRef]

[10] Çolak F, Savaroğlu F, Ilhan S. Antibacterial and antifungal activities of Arum maculatum L. leaves extracts. JABS. 2009; 3: 13-16.

[11] Jaradat N, Abualhasan M. Comparison of Phytoconstituents, Total Phenol Contents and Free Radical Scavenging Capacities between Four Arum Species from Jerusalem and Bethlehem. Pharm Sci. 2016; 22: 120-125. [CrossRef]

[12] Valli G, Giardina EG. Benefits, adverse effects and drug interactions of herbal therapies with cardiovascular effects. J Am Coll Cardiol. 2002; 39: 1083-1095. [CrossRef]

[13] Knufman NM, van der Laarse A, Vliegen HW, Brinkman CJ. Quantification of myocardial necrosis and cardiac hypertrophy in isoproterenol-treated rats. Res Commun Chem Pathol Pharmacol. 1987; 57: 15-32.

[14] Jana S, Patel D, Patel S, Upadhyay K, Thadani J, Mandal R, Das S, Devkar R. Anthocyanin rich extract of Brassica oleracea L. alleviates experimentally induced myocardial infarction. PLoS One. 2017; 12: e0182137.[CrossRef]

[15] Soraya H, Rameshrad M, Mokarizadeh A, Garjani A. Metformin attenuates myocardial remodeling and neutrophil recruitment after myocardial infarction in rat. Bioimpacts. 2015; 5: 3-8. [CrossRef]

[16] Tukozkan N, Erdamar H, Seven I. Measurement of total malondialdehyde in plasma and tissues by highperformance liquid chromatography and thiobarbituric acid assay. Firat Tip Dergisi. 2006; 11: 88-92. 
[17] Ziaee M, Khorrami A, Ebrahimi M, Nourafcan H, Amiraslanzadeh M, Rameshrad M, Garjani M, Garjani A. Cardioprotective Effects of Essential Oil of Lavandula angustifolia on Isoproterenol-induced Acute Myocardial Infarction in Rat. Iran J Pharm Res. 2015; 14: 279-289.

[18] Fathiazad F, Matlobi A, Khorrami A, Hamedeyazdan S, Soraya H, Hammami M, Maleki-Dizaji N, Garjani A.Phytochemical screening and evaluation of cardioprotective activity of ethanolic extract of Ocimum basilicum L. (basil) against isoproterenol induced myocardial infarction in rats. Daru. 2012; 20: 87. [CrossRef]

[19] Mukherjee S, Mukherjee N, Saini P, Roy P, Babu SP. Ginger extract ameliorates phosphamidon induced hepatotoxicity. Indian J Exp Biol. 2015;53:574-584.

[20] Suchal K, Malik S, Gamad N, Malhotra RK, Goyal SN, Bhatia J, Arya DS. Kampeferol protects against oxidative stress and apoptotic damage in experimental model of isoproterenol-induced cardiac toxicity in rats. Phytomedicine. 2016; 23: 1401-1408.[CrossRef]

[21] Reddy NM, Mahajan UB, Patil CR, Agrawal YO, Ojha S, Goyal SN. Eplerenone attenuates cardiac dysfunction and oxidative stress in beta-receptor stimulated myocardial infarcted rats. Am J Transl Res. 2015; 7: 1602-1611.

[22] Frangogiannis Ng SCWEML. . The inflammatory response in myocardial infarction. Cardiovasc Res. 2002; 53(1): 3147.

[23] Christia P, Frangogiannis NG. Targeting inflammatory pathways in myocardial infarction. Eur J Clin Invest. 2013; 43: 986-995.[CrossRef]

[24] Steffens S, Montecucco F, Mach F. The inflammatory response as a target to reduce myocardial ischaemia and reperfusion injury. Thromb Haemost. 2009; 102: 240-247. [CrossRef]

[25] Libby P, Maroko PR, Bloor CM, Sobel BE, Braunwald E. Reduction of experimental myocardial infarct size by corticosteroid administration. J Clin Invest. 1973; 52: 599-607. [CrossRef]

[26] Jolly SR, Kane WJ, Hook BG, Abrams GD, Kunkel SL, Lucchesi BR. Reduction of myocardial infarct size by neutrophil depletion: effect of duration of occlusion. Am Heart J. 1986; 112: 682-690.[CrossRef]

[27] Romson JL, Hook BG, Kunkel SL, Abrams GD, Schork MA, Lucchesi BR. Reduction of the extent of ischemic myocardial injury by neutrophil depletion in the dog. Circulation. 1983; 67: 1016-1023. [CrossRef]

[28] Vinten-Johansen J. Involvement of neutrophils in the pathogenesis of lethal myocardial reperfusion injury. Cardiovasc Res. 2004; 61: 481-497. [CrossRef]

[29] Al-Yahya M, Raish M, AlSaid MS, Ahmad A, Mothana RA, Al-Sohaibani M, Al-Dosari MS, Parvez MK, Rafatullah S. 'Ajwa' dates (Phoenix dactylifera L.) extract ameliorates isoproterenol-induced cardiomyopathy through downregulation of oxidative, inflammatory and apoptotic molecules in rodent model. Phytomedicine. 2016; 23: 1240-1248. [CrossRef]

[30] Yousefi K, Fathiazad F, Soraya H, Rameshrad M, Maleki-Dizaji N, Garjani A. Marrubium vulgare L. methanolic extract inhibits inflammatory response and prevents cardiomyocyte fibrosis in isoproterenol-induced acute myocardial infarction in rats. Bioimpacts. 2014; 4: 21-27. [CrossRef]

[31] Shukla M, Gupta K, Rasheed Z, Khan KA, Haqqi TM. Consumption of hydrolyzable tannins-rich pomegranate extract suppresses inflammation and joint damage in rheumatoid arthritis. Nutrition. 2008; 24: 733-743. [CrossRef]

[32] Yao Y, Yang X, Shi Z, Ren G. Anti-inflammatory activity of saponins from quinoa (Chenopodium quinoa Willd.) seeds in lipopolysaccharide-stimulated RAW 264.7 macrophages cells. J Food Sci. 2014; 79: H1018-1023.[CrossRef]

[33] Souto AL, Tavares JF, da Silva MS, Diniz Mde F, de Athayde-Filho PF, Barbosa Filho JM. Anti-inflammatory activity of alkaloids: an update from 2000 to 2010. Molecules. 2011; 16: 8515-8534. [CrossRef]

[34] Pan MH, Lai CS, Ho CT. Anti-inflammatory activity of natural dietary flavonoids. Food Funct. 2010 ; 1: 15-31. [CrossRef]

[35] Khalaf N, Naik R, Shakya A, Shalan N, Al-Othman A. Antioxidant, anti-inflammatory and anti-diarrheal activity of ethanolic extract of medicinal plants grown in Jordan and Palestine. Orient. J. Chem. 2015; 31: 1923-1928. [CrossRef]

[36] Alencar VB, Alencar NM, Assreuy AM, Mota ML, Brito GA, Aragao KS, Bittencourt FS, Pinto VP, Debray H, Ribeiro RA, Cavada BS. Pro-inflammatory effect of Arum maculatum lectin and role of resident cells. Int J Biochem Cell Biol. 2005; 37: 1805-1814. [CrossRef]

[37] Ho E, Karimi Galougahi K, Liu CC, Bhindi R, Figtree GA. Biological markers of oxidative stress: Applications to cardiovascular research and practice. Redox Biol. 2013; 1: 483-491. [CrossRef] 
[38] Janakat S, Al-Thnaibat O. Antilipoperoxidative Effect of Three Edible Plants Extracts: Viscum Album, Arum Dioscoridis and Eminium Spiculatum. J Food Qual. 2008;31:1-12. [CrossRef]

[39] Lewandrowski K, Chen A, Januzzi J. Cardiac markers for myocardial infarction. A brief review. Am J Clin Pathol. 2002; 118 Suppl: S93-599.

[40] Kemp M, Donovan J, Higham H, Hooper J. Biochemical markers of myocardial injury. Br J Anaesth. 2004; 93: 63-73. [CrossRef]

This is an open access article which is publicly available on our journal's website under Institutional Repository at http://dspace.marmara.edu.tr. 